\title{
Cleaning Up the Big Muddy: A Meta-Synthesis of the Research on the Social Impact of Dams
}

\section{HIGHLIGHTS}

- Very first systematic review (meta-synthesis) of the research on the social impact of dams

- Biases in the literature identified, e. g. large dams over-studied, too much focus solely on resettlement area impacts as well as impacts 5-10 years expost resettlement

- Implications of these biases for our understanding of the topic at hand are discussed

\section{ABSTRACT}

Scholars have been exploring the social impacts of dams for over 50 years, but a lack of systematic approaches has resulted in many research gaps remaining. This paper presents the first systematic review of the literature on the social impacts of dams. For this purpose, we built a sample of 217 articles published in the past 25 years via key word searches, expert consultations and bibliography reviews. All articles were assessed against an aggregate matrix framework on the social impact of dams, which combines 27 existing frameworks. We find that existing literature is highly biased with regards to: perspective (45\% negative versus $5 \%$ positive); dam size (large dams are overrepresented); spatial focus (on the resettlement area); and temporal focus (5-10 years ex-post resettlement). Additionally, there is bias in terms of whose views are included, with those of dam developers rarely examined by scholars. These gaps need to be addressed in future research to advance our knowledge on the social impact of dams to support more transparency in the tradeoffs being made in dam development decisions.

\section{KEYWORDS}

large dams; hydropower; social impact; resettlement; meta-synthesis; framework 


\section{INTRODUCTION}

In recent decades, policy-makers around the world have mostly shunned hydropower. Particularly upon publication of the seminal report by the World Commission on Dams (WCD) in 2000, with its conclusion that "in too many cases an unacceptable and often unnecessary price has been paid to secure [dams'] benefits, especially in social and environmental terms" (WCD, 2000, p. 18), the rate of construction of dams declined (Schneider, 2013). Dams are an emotive and contentious topic partly due to the high potential for social impacts. Scudder (2011) estimates that more than 200 million people were displaced due to infrastructure projects in the previous century; possibly 80 million (40 percent) of these were displaced due to dams.

However, dams may now be about to make a comeback with major players reconsidering their stance. Chinese firms and banks have increasingly developed dams since the early 2000s, particularly in Southeast Asia, seeking new profit pools (Urban et al., 2012, p. 313). The U.S. Department of Energy announced in 2012 that it aims to boost hydropower capabilities by as much as 15 percent in coming years (Pitt, 2013). The World Bank refocused on investments in hydropower projects in 2013 after largely abandoning the sector for about a decade (Schneider, 2013). A case in point is the 4.8 GW Inga 3 Project in the Democratic Republic of Congo (Sanyanga, 2015).

Scientists have explored the social impacts of dams since the 1960s (Adeniyi, 1976; Scudder, 1968; Shields, 1974; Singg and Webb, 1979; Sutton, 1977). Almost five decades have passed since Scudder identified a need for a systematic body of evidence to be developed via longitudinal studies utilizing hydropower development as a "quasi-laboratory [for accelerated change] within which to work" (Scudder, 1968, p. 169). Since then a wealth of studies on the social impacts of dams have been undertaken, conducted by scholars from a variety of disciplines - from anthropology to political science, human geography, engineering and even biology (Bakker, 1999; Beck et al., 2012; Lerer and Scudder, 1999; Tullos et al., 2013; Wang et al., 2013).

However, various scholars point out that many research gaps remain (Cernea, 2004; Scudder, 2015; Tilt, Braun, and He, 2009; Vanclay, 2002). A reason may be the complexity of dams' social impacts with a multitude of social impacts occurring over various time, space and value dimensions (on the complexity of the resettlement process: Bartolome et al. (2000), de Wet (2012) or de Wet (2006)). Indeed, dams' impacts are more complex than those of other infrastructure projects in many ways. Dams frequently serve several purposes, e.g. electricity provision, irrigation and flood control. WCD (2000) estimates that one third of 
dams serve two or more purposes, with the share of multipurpose dams increasing in recent years. Furthermore, dams have a spatial impact far beyond the construction activities and the associated displacement, the key spatial impact areas of most infrastructure projects. Dams’ social impacts affect upstream populations, e.g. via restrictions on water use in order to fill the reservoir (Duflo and Pande, 2007), downstream populations, e.g. via benefits from irrigation water and flood protection; and entire countries, e.g. via electricity generation. Lastly, dams are among the most long-lived infrastructure projects, and social impacts can be considered over the entire operational timeframe. Dams may run for over 100 years, e.g. construction of Arizona's still functioning Theodore Roosevelt Dam was completed 104 years ago (SRP, 2015), whereas, for instance, a coal-fired power plant may only last for 30 years (Cleetus et al., 2012).

A single scholar or a small team of scholars usually cannot comprehensively study the breadth of these social impacts even for a single dam. Indeed, huge teams are required nowadays to complete commercial social impact assessments (SIA) which usually only consider dams' social impacts 5-10 years after project completion in the resettlement area. For instance, more than 100 experts were needed to complete the impact assessment for Myanmar's controversial Myitsone Dam (CPI, 2011, p. 1). Because scholars usually cannot employ the resources necessary to comprehensively study dams' social impact, particular components or dimensions of social impact are focused on. However, if no systematic review of the whole body of literature on the social impact of dams is carried out regularly (objectively showcasing which areas of social impact are over- or understudied), various scholars may focus on highly similar or identical areas of social impact. This may lead to various biases in the literature and our understanding of the social impact of dams.

As far as we are aware, no systematic review of the literature on the social impact of dams has ever been undertaken. This paper aims to provide such a systematic review. Via this review, research gaps in the current body of literature on the social impact of dams are quantified to objectively showcase which dimensions and components of social impact are truly understudied. Thus, this paper hopes to offer definitive guidance regarding future research on the social impact of dams.

The remainder of this paper is organized as follows. In section 2, we explain why we chose to conduct a meta-synthesis on the social impact of dams (instead of a meta-analysis or narrative review). In section 3, we outline how we developed a sample of the literature. Then we explain the chosen assessment framework for this sample in section 4. Section 5 describes the coding rules adopted, section 6 the 
findings of our analysis. Our results are discussed in section 7. We summarize our argument in section 8 .

\section{METHODS}

Meta-analysis, meta-synthesis and narrative review are three key approaches to literature review. Meta-analysis is considered the most robust approach to cleaning up "the big muddy" of a scholarly body of research. ${ }^{1}$ During a meta-analysis, the scholar systematically develops a sample of articles assessing identical or highly similar research questions. Then, empirical findings of studies at hand are aggregated. Herein, the meta-analysis helps to maximize the sample size which, in turn, may enhance the external validity of previous findings (Glass, 1976). For the topic at hand insufficient quantitative evidence exists for a meta-analysis. Indeed, "what is striking [...], is the absence of systematic empirical evidence on how the average large dam affects welfare" (Duflo and Pande, 2007, p. 602).

The evidence that is available on the social impact of dams is largely from qualitative research, conducted by scholars from various disciplines. Therefore, we chose to undertake a meta-synthesis. During a meta-synthesis, the scholar also systematically develops a sample of articles on identical or highly similar research questions. Then, findings in the article are assessed against a framework.

Via a meta-synthesis, scholars quantify which parts of a theoretical framework have not yet been investigated sufficiently offering guidance to future researchers (Cronin, Ryan, and Coughlan, 2008). Hence, a meta-synthesis may be able to help integrate and focus the literature on the topic at hand.

Both meta-analyses and meta-syntheses are replicable. Thus, they are the "rigorous alternative to the casual, narrative discussions of research studies" (Glass, 1976, p. 3 ), the narrative review. Neither sample selection nor sample assessment is usually systematized within a narrative review. As a result, the narrative review cannot be replicated and may lead to subjective, possibly misleading summaries of the research.

1 We owe the phrase "cleaning up the big muddy" to Sleesman et al. (2012) whose meta-analytic review of the determinants of escalation of commitment inspired the methodological approach chosen in this paper. 


\subsection{CREATING A SAMPLE}

The first step when conducting a meta-synthesis is the systematic creation of a sample. We generated our initial sample of articles on the social impact of dams via a three-step-process, conducted in early 2015. Firstly, keyword searches were undertaken in seven databases: Thomson Reuters' Web of Science, the University of Oxford Search Oxford Libraries Online (SOLO), Elsevier's Scopus, ProQuest, Columbia International Affairs Online (CIAO), OpenGrey and Anthropology Plus. Searches included any scholarly journal articles, grey literature, book chapters and books that featured combinations of the keywords - social impact, social effect, human effect, resettlement, forced migration, agricultural productivity, dam and hydropower - as well as various plural forms of the keywords at hand. No starting date was set. Searches were not restricted to any particular discipline. (To enhance readability, we refer to every piece of literature as an 'article' for the remainder of this paper. However, an 'article' may also encompass a report, book, book chapter or dissertation.)

Secondly, experts in the field were invited to double-check and possibly add articles to this initial sample (the anonymous reviewers of this paper also suggested to add four more pieces to this sample). Thirdly, experts identified key pieces of literature on the social impact of dams, the bibliographies from which were added to our sample. Bibliographies of recent dissertations on the topic were also included, as well as articles which are allegedly key pieces of literature on the topic according to the International Association for Impact Assessment (IAIA, 2009).

Overall, we included the bibliographies of Lerer and Scudder (1999), Strobl and Blanc (2013), and Tullos et al. (2010) as well as all articles published by the journal Water Nepal to our sample. These inclusions were based upon recommendations of experts in the field. Furthermore, we included the bibliographies of the recent dissertations by Matthews (2013) and Plummer (2013) as well as the bibliographies by Égré and Senécal (2003) and Tilt et al. (2009), key pieces of literature on the topic according to IAIA (2009), to our sample. Examples of key books/book chapters in our sample are The Future of Large Dams by Scudder (2006), Silenced Rivers: The Ecology and Politics of Large Dams by McCully (2001) or Water Resources: Environmental Planning, Management, and Development by Biswas (1997). We acknowledge, though, that our sample is likely biased towards peer-reviewed articles, while possibly not including all major books on the topic, since search engines such as Thomson Reuters' Web of Science do not index many books of interest to us. An example of a book not indexed by Thomson Reuters' Web of Science would be The Future of 
Large Dams by Scudder (2006). We note that our sample also includes WCD thematic reviews such as Bartolome et al. (2000) and Colchester (2000) which constitute part of the WCD knowledge base, the foundation of the report by the WCD.

Our initial sample based upon this three-step-process comprised 1641 articles. We then refined this sample, removing any article from the sample if at least one of the six criteria below was met:

- Repetition: Pieces appearing more than once in the initial list;

- Focus: Pieces unrelated to the social impacts of dams²;

- Language: Pieces not published in English or German;

- Popular press: Pieces on the topic published in the popular press, e. g. Wall Street Journal, the New York Times;

- Conference reports: Pieces related to the social impact of dams, but only summarizing the outcomes of conferences; or,

- Date of publication: Pieces published prior to $1990 .^{3}$

Our refined sample based upon these criteria comprised 217 articles. We do not presume to have collected all articles on the social impact of dams in this sample. However, we believe, given the systematic approach adopted, we have identified a set that is fairly representative of the work carried out by the research community.

\subsection{CHOOSING AN ASSESSMENT FRAMEWORK}

Various frameworks on the social impact of dams exist that could have been employed to assess our sample. We chose the matrix framework on the social impact of dams, developed by Kirchherr \& Charles (2016) as our assessment framework. It is based upon the aggregation of 27 different frameworks within the relevant literature.

2 Whenever we were not entirely certain - based upon reading the abstract and skimming the body of the article - if the article in question was truly unrelated to the social impact of dams, we chose to include it in the sample. We would then only exclude it based upon an in-depth-review of the article during the coding process.

3 We chose to exclude pieces published prior to 1990 for two reasons. First, we feared that we may not be able to gather a representative sample of articles published more than 25 years ago since many of these are not digitized yet. Second, we assume that key insights and ideas from influential articles published prior to 1990, e. g. Scudder \& Colson (1982), would be reflected in the approaches taken by those articles in our sample in any case. 
Kirchherr \& Charles (2016) argue that no other key framework on the topic captures dams' social impacts as comprehensively. First, the matrix framework systematically spells out the social impact of dams from a space, time and value perspective. Furthermore, it exhaustively outlines dams' social impact components while emphasizing their interlinked nature. A visualization of this framework is depicted in Figure 1. Two particular terms are used to characterize the parts of the framework: components and dimensions. The components of social impact are variables to consider when assessing the social impacts of dams, grouped into themes of infrastructure, livelihood and community. The dimensions of social impact are the variables' context, grouped into themes of space, time and value. Accordingly, any social impact component may occur alongside the different dimensions of social impact. We chose the different dimension and components within the framework as our coding categories for the meta-synthesis.

\section{FIGURE 1: TAXONOMY REGARDING THE SOCIAL IMPACTS OF DAMS}

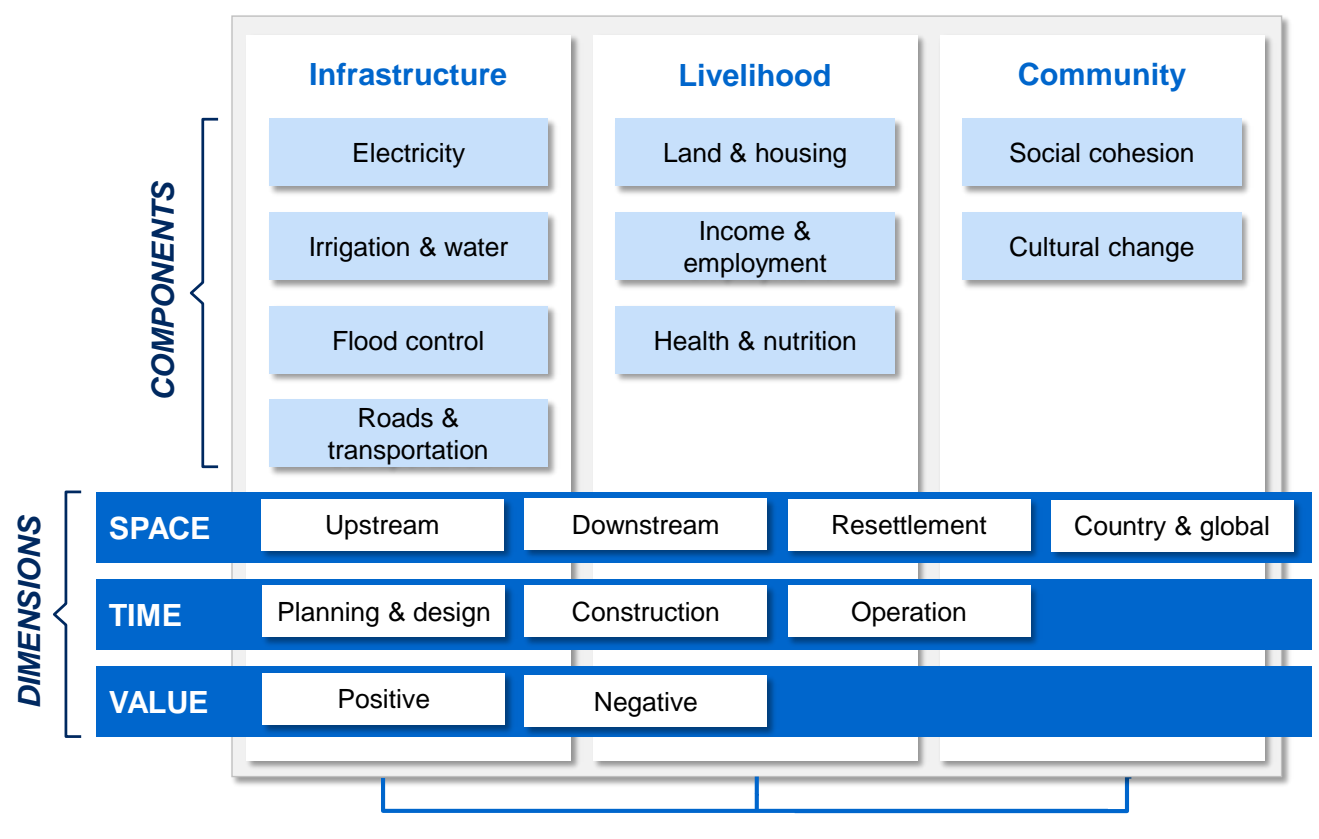

SOURCE: Kirchherr \& Charles (2016)

Furthermore, we adopted a unit-of-analysis perspective within the spatial dimension of the framework and tracked if there is a focus within each article, e.g. on the private sector (with a particular focus on dam developers), civil society (including NGOs, resettled communities, with a particular focus on vulnerable groups, i.e. women, indigenous and landless people) or government (namely, domestic government, foreign government, and international donors). We also tracked: the journal, year of publication, whether it was grey literature or not, the 
regional focus of the publication, whether it focused on a single case study, whether the article employed a framework for analysis and whether the article adopted a qualitative, quantitative or mixed method approach.

\subsection{ON CODING RULES}

Synthesizing qualitative findings via a meta-synthesis will always remain more subjective than synthesizing quantitative findings via a meta-analysis. The effects of subjectivity may only be "minimized through carefully applied criteria for [sample development and] evaluation" (Beyea and Nicoll, 1998, p. 877).

We utilized NVivo 10 to ensure traceability of coding decisions and the objectivity of our evaluation. A preliminary set of nine articles was coded by all three authors of this article in order to establish, challenge and refine a set of initial coding rules. Based on the results the coding rules were refined. For those articles where the coding results differed by more than one article (11\%), we discussed our coding decisions and attempted to refine our coding rules. As a consequence, a coding rule booklet with detailed information for each node was developed (and further refined throughout the coding process).

Within the booklet, a four-step-coding process for each article was defined. First, we would analyze in-depth the abstract of the article. Second, we would read indepth its conclusion. Third, we would skim the remaining parts of the article with a particular focus on headlines, visualizations and its methods part. Finally, we would run a key word search on every node defined as well as additional key word searches.

All articles were eventually coded by two of the three authors of this article. Within our results discussion, we showcase the coding values obtained by both authors. This focus on ranges instead of seemingly definite values ought to emphasize our perception regarding the relativity of the data; our coding results remain (at least partly) subjective.

Our discussion of results is based upon the structure of the matrix framework. After giving an overview regarding the entire sample, we present findings first from a dimension and then from a component perspective.

\section{RESULTS}

In this section we present results drawing on our entire sample of 217 articles. It is recognized that some articles will have impacted the literature (and, as a 
consequence, scholars' views regarding the social impact of dams) much more than others. However, it was not considered feasible to present analyses weighting articles according to their importance within the literature. After presenting an overview of our results, the rest of this section is organized by the taxonomy presented in Figure 1.

\subsection{OVERVIEW}

Of the 217 articles in the sample, 39 (18\%) are grey literature, e.g. Master's theses, working papers or conference proceedings. The papers are spread across various journals. The most common journal within our sample is the International Journal of Water Resources Development featuring 22 articles. Searches within Anthropology Plus, CIAO and OpenGrey yielded no or almost no relevant results.

There has been a growth in the literature on social impacts of dams. 123 of the 217 articles (57\%) were published in the past 10 years. Only 48 of the articles were released between 1990 and 2000, as depicted in Figure 2. This growth is in line with the growth of the overall literature on the topic at hand. For instance, Esteves et al. (2012) find 120 social impact assessment (SIA) articles for 1993 and 624 SIA articles for 2010. This growth (with a compound annual growth rate of $14 \%$ from 1995 onwards) likely outpaces the overall growth in the social sciences literature, estimated at 9\% for the period of 1997-2006 (Larsen and von Ins, 2010, p. 589). However, the small number of articles identified as published during the 1990s may also reflect data collection challenges; many of the articles from the 1990s may not be digitized yet. While we attempted to identify non-digital articles, e.g. via various library searches, it is likely that we did not manage to identify every relevant article from this time period.

Only 55 articles (25\%) utilize a framework within their analysis. Within these 55 articles 27 different frameworks are employed. Herein, the Impoverishment Risks and Reconstruction (IRR) Model by Cernea (1990) is the most widely used framework; it is employed in seven papers (sometimes in a modified version). Frameworks have become more popular overall in recent years. Whereas only 6 out of 46 articles (13\%) published from 2001-2005 employed a framework, 18 out of 69 articles (26\%) published from 2011-2015 employed one. 


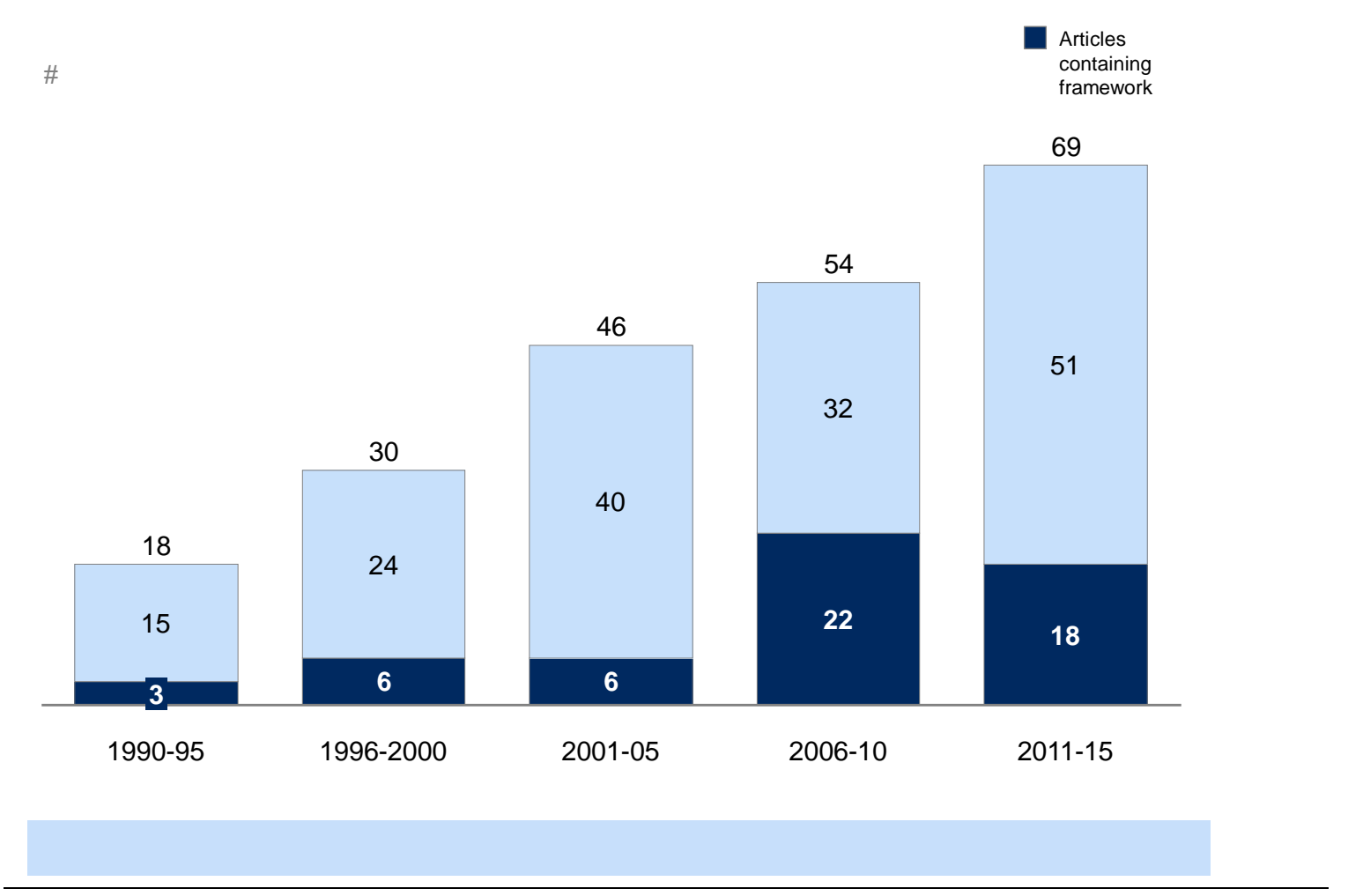

There is a geographic bias in the literature, but it reflects the locations of large dams: $54 \%$ of articles in our sample are focused on dams in Asia, only $13 \%$ on Africa, $9 \%$ on the Americas, and 4\% on Europe. 19\% of papers adopt a global perspective. China is the most commonly studied country within the sample with 31 papers, followed by India with 27 papers. According to WCD (2000), almost half of the world's large dams are located in China. Of the 173 papers with a regional focus, approximately 80 papers (instead of 30) would be on China if the literature accurately reflected the global distribution of dams from a country perspective. The overall regional distribution within our sample largely reflects the actual distribution of large dams at the end of the last century (Figure 3). The data depicted in this figure regarding actual geographical distributions of large dams was collated by WCD (2000, p. 8) and is based on (allegedly representative) 1998 data from the International Commission on Large Dams (ICOLD). Only Africa is significantly overrepresented in the scholarly literature (with 17\% of articles on Africa, but only 3\% of large dams in Africa). Europe and the Americas are slightly underrepresented (Europe by 6\%, the Americas by $8 \%)$. 


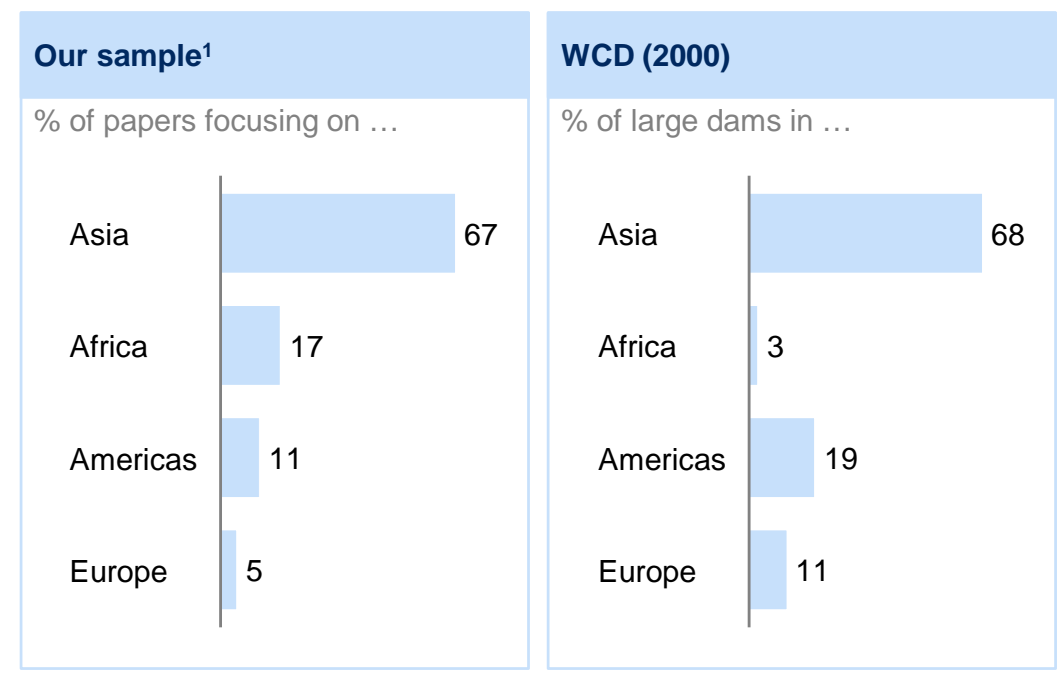

1 Papers adopting a global perspective excluded from this analysis

Most scholarly papers only focus on a single dam, with a few dams particularly over-studied, despite the fact that the social impacts found in these case studies may not be representative for all dams. Indeed, 44\% of papers within our sample focus on a single dam, $12 \%$ focus on just two cases, and only $23 \%$ analyze more than ten cases. Sabnis (2001, p. 99) argues that the Sardar Sarovar Dam would be "by far the most studied water project in the developing world, especially in social and environmental terms". This claim is corroborated via our sample. Indeed, we found 17 papers on the Sardar Sarovar Dam, more than for any other dam project. The second most studied dam is China's Three Gorges Dam with 16 papers. 3 papers each were published on the Nam Theun 2 Dam in Laos, the Saguling Dam in Indonesia, the Son La Dam in Vietnam, and the Katse Dam in Lesotho. All other dams within the single case study set of our sample were only studied once or twice.

The preference for analyses of single cases in our sample is matched by an even stronger preference for qualitative analyses. $58 \%$ of papers within our sample adopt only or predominantly qualitative methods. $26 \%$ adopt a mixed methods approach and just $16 \%$ are solely or predominantly quantitative in their analysis. Although a correlation between qualitative analysis and studies of single dams (or between quantitative analysis and studies of more than ten dams) might be expected, no clear correlation is found. In fact, $51 \%$ of quantitative analyses in 
our sample studied just a single case. A reason may be that undertaking a costbenefit-analysis for a single dam is already such a complex endeavor, as evidenced by Tajziehchi et al. (2013), that those adopting quantitative approaches do not opt for more dams to be included in their analysis for feasibility reasons.

The prominence of Sardar Sarovar Dam (163m) and China's Three Gorges Dam $(181 \mathrm{~m})$ in our sample also significantly impacts the average dam height, as well as power capacity and construction time of a dam within the single case study set of our sample. The Three Gorges Dam is the largest power producing facility in the world with a capacity of 22,500 MW. This is reflected in Table 1, with a greater average height and capacity in our sample as compared with the (supposedly representative) dam samples by Ansar et al. (2014) as well as Nombre (2014). ${ }^{4}$

Table 1: Dam height, construction time and power capacity in different samples

\begin{tabular}{|l|c|c|c|}
\cline { 2 - 4 } \multicolumn{1}{l|}{} & \multicolumn{1}{c|}{$\begin{array}{c}\text { Ansar et al. } \\
\text { (2014) }\end{array}$} & Nombre (2014) & Our sample \\
\hline Average dam height & $77 \mathrm{~m}$ & $25 \mathrm{~m}$ & $145 \mathrm{~m}$ \\
\hline $\begin{array}{l}\text { Average power } \\
\text { capacity }\end{array}$ & $487 \mathrm{MW}$ & $100 \mathrm{MW}$ & $5143 \mathrm{MW}$ \\
\hline $\begin{array}{l}\text { Average } \\
\text { construction time }\end{array}$ & 8.6 years & $<3$ years & 6 years \\
\hline Sample size & 245 & 50,000 & 96 \\
\hline
\end{tabular}

The parameters for our study in Table 1 reflect that scholars focus on extremely large dams when studying social impacts of dams. Nombre (2014, p. 2) already warned, regarding the sample by Ansar et al. (2014), that this may be "a total misrepresentation of the 50,000 large dams existing today". Our sample may be even more misrepresentative. This is corroborated when comparing average dam heights with those dams funded by the Inter-American Development Bank (IADB) (Figure 4): while the typical dam funded by IADB is only between 15 and 100 meters high, only $29 \%$ of dams in our sample have this height.

\footnotetext{
4 If a dam appeared more than once (e.g. $5 x$ ) in our sample, we would also count this dam several times (in this case: $5 x$ ) for this analysis.
} 


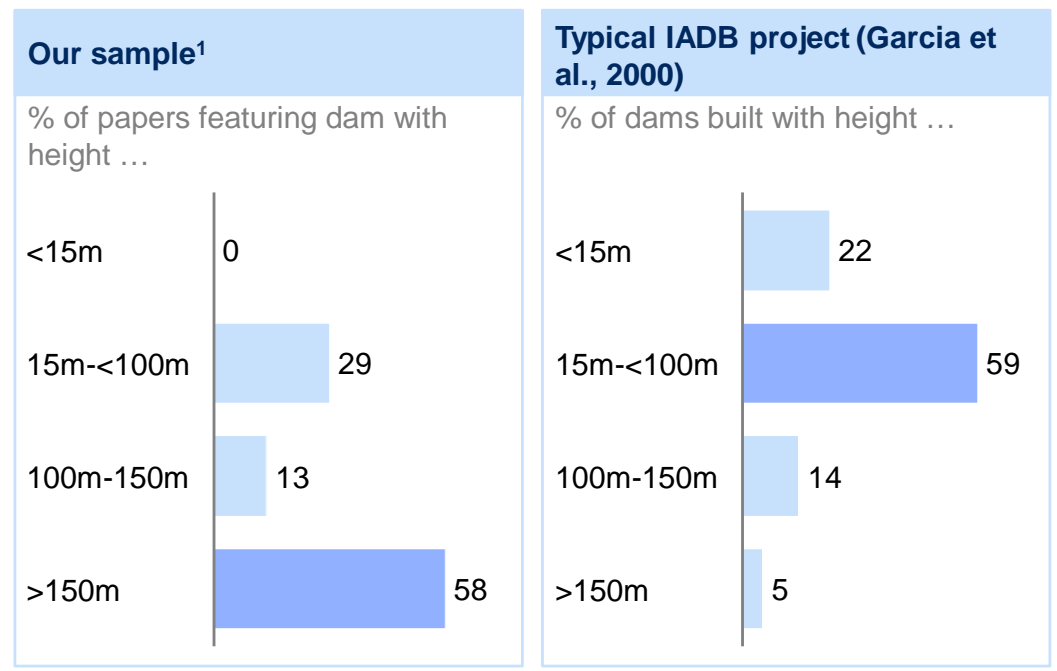

1 Analysis based upon those papers focusing on single dam - Double-counting of those papers featuring identical dam

We believe that the argument that small dams are not studied because their impacts are not of concern does not hold. Indeed, Abbasi \& Abbasi (2011) and Kibler \& Tullos (2013) point out that small dams’ environmental impacts may exceed those of large dams from a river basin perspective, particularly with regard to habitat and hydrologic change. In his seminal paper on the impacts of small dams, Gleick (1992) also implied that a series of small dams may submerge more land than a single large dam. Thus, small dams can also cause significant displacement. The exact social impacts of small dams are not well understood, though, and more research is needed to investigate them particularly from a river basin perspective.

\subsection{DIMENSIONS OF SOCIAL IMPACT}

This section provides further insight into our findings based on the dimensions of social impact outlined in Figure 1: Space, time and value.

\section{A. SPACE}

The resettlement area is by far the most adopted spatial perspective when studying the social impact of dams; $85 \%-87 \%$ of articles in our sample focus on it. In the early stages of the study of dam impacts, Shields (1974, p. 268) already noted that resettlement "has probably received more attention than any other category of 
social impact". After all, it is "largely considered the most severe form of social impact generated by dams" (Égré and Senécal, 2003, p. 216).

Only $29 \%-31 \%$ of articles focus on downstream impacts corroborating the impression by Cernea $(2004$, p. 6 ) that "downstream impacts have been understudied and overlooked by dam planners". The only comprehensive study identified on downstream impacts is Richter et al. (2010); the authors estimate that 472 million people worldwide may have been impacted by dam construction. Upstream impacts are also largely overlooked, as already hypothesized by Greathouse et al. (2006). Only 16\% of articles focus on these impacts.

Country and global impacts are accounted for in $41 \%$ of articles. Pieces solely adopting this perspective are usually published by economists. Examples include Duflo and Pande (2007), exploring productivity and distributional effects of large dams in India, and Strobl and Strobl (2011), investigating cropland productivity implications of large dams in Africa.

\section{B. $\underline{\text { TIME }}$}

The operation phase is the most studied time period within the literature. 65\%$67 \%$ of articles focus on this phase. Within our set of single case studies, $59 \%$ focus on this phase. Concretely, $36 \%$ of these articles were published up to 10 years after completion of the dam at question, $8 \%$ between 11 to 20 years after completion and $17 \%$ more than 20 years after completion.

Scudder (1997) complained of a paucity of research designed to assess longitudinal impacts. Our sample indicates that scholars do investigate long-term social impacts, but are less focused on longitudinal ones. Key examples of studies on long-term impacts are Gunawan et al. (2013), exploring the impacts on those resettled due to Indonesia's Saguling Dam, completed more than 25 years ago, and Takesada (2009), who interviewed those resettled because of Japan's Ikawa Dam 50 years after their resettlement. A rare example of longitudinal research over multiple decades is the case of Zambia's Kariba Dam with an effort to study second and even third generation social impacts of the dam currently ongoing, according to Thayer Scudder (personal communication, 2016). The study on the Kariba experience by Colson (1971) was even called "the best case study of resettlement impacts [overall]” (Scudder, 2012, p. 45).

The ongoing research on the Kariba Dam resettlement is likely to be unique in the literature since a lack of second generation research (and beyond) was identified in our sample. Indeed, all scholars within our sample only focus on those resettled, whereas social impacts may even impact the descendants of those resettled, as 
already suggested by the Scudder and Colson relocation model (1982). Not a single article within our sample focuses on these second generation impacts. We acknowledge that these second generation impacts may be extremely difficult to factor out due to various confounding variables (e.g. government policy, climate change).

A more prominent topic - at least in recent years - within those articles focusing on the operation phase is the decommissioning of dams. For instance, Qi and Altinakar ( 2012) investigate dam-break flood management in Pakistan. Wiejaczka et al. (2014) explore perceptions regarding the risk of dam breaks in Poland. These articles on the end of a dam's life cycle may be seen as a response to WCD (2000). Herein, the authors argued that "more studies are needed to address the costs, benefits and impacts of decommissioning as the stock of dams ages and choices must be made between refurbishing and decommissioning" (WCD, 2000, p. 11).

The planning and design phase is least studied within our sample: only $19 \%-22 \%$ of articles address this phase. Plummer (2013, p. 7) notes that "it is surprising that this issue [of social impacts during the planning and design phase] has not been the subject of significant earlier study"; after all, WCD (2000, p. 19) outlined that "free, prior and informed" consent of people to be moved ought to be obtained during the planning and design phase - a challenging demand which would offer plentiful opportunities for scholarly study if implemented (an example of a project repeatedly upholding this principle was Laos' Nam Theun 2 Dam) (Scudder et al., 1997, p. 25 ff.). A key reason for the scarcity of studies on planning and design phase impacts may be lack of transparency and accessibility, as the public opposition to dams that has developed in the past 45 years (McAdam et al., 2010, p. 402) has led to difficulty in accessing information during the planning and design phase. For instance, we were not able to carry out envisaged research on ex-ante resettlement impacts in Myanmar due to governmental access constraints.

\section{VALUE}

Almost all articles within our sample (93\%-95\%) report on at least one negative social impact, while about two thirds report on at least one positive social impact. Only 5\%-6\% of articles are largely positive regarding dams' social impacts; $44 \%-$ $46 \%$ are largely negative, $49 \%-50 \%$ balanced.

Initially, we thought that coding articles as 'largely positive', 'largely negative' or 'balanced' would be highly subjective. However, our ranges showcase that this may not be the case. Indeed, most authors in our sample are rather vocal and explicit regarding their view on the social impact of dams. An example for an article we coded as 'largely negative' would be Finley-Brook and Thomas (2011); 
their research was funded by a university research grant. The authors' article on hydropower development in Panama is titled "Renewable Energy and Human Rights Violations". An example for an article coded as 'largely positive' would be Gunawan et al., (2013, p. 25), concluding that "the majority of the resettlers perceived their livelihoods as better after resettlement". This research was mostly funded by the Mitsui \& Co., Ltd. Environment Fund, a large Japanese conglomerate also involved in the energy business.

Our findings regarding value corroborate impressions by previous scholars. Barrow (2000, p. 27) noted that "there has been a tendency to stress negative impacts". Vanclay (2002, p. 189) wrote that "despite rhetoric in SIA about considering the benefits $[\ldots]$ that there is no consideration given to the indicators that would be necessary to describe [them]".

Articles published within peer-reviewed journals and books seem to be more critical towards dams than the grey literature. Indeed, we coded $47 \%-48 \%$ of articles as "largely negative" within peer-reviewed journals and books, compared to only $29 \%-39 \%$ within the grey literature. $32 \%$ of grey literature papers were dissertations by students. A key reason for the less critical grey literature may be the source of funding. 34\% of papers within grey literature were either funded by governments, international donors or the dam industry, all of which are usually seen as advocates of dam projects (Nüsser, 2003, p. 22).

Overall, articles that were largely positive regarding the social impact of dams seem to take into account different components than articles that were largely negative. Articles that were largely positive tend to focus on infrastructure impacts, whereas community impacts are underrepresented compared to articles that were largely negative. For instance, virtually every single article that was largely positive discusses electricity impacts, while only $64 \%-70 \%$ of articles that were largely negative do so. Flood control aspects are discussed in $57 \%-70 \%$ of articles that were largely positive (largely negative: 36\%-38\%). Meanwhile, social cohesion is mentioned in $57 \%-58 \%$ of largely negative articles, but only $36 \%-40 \%$ of largely positive articles. This analysis is summarized in Figure 5. 


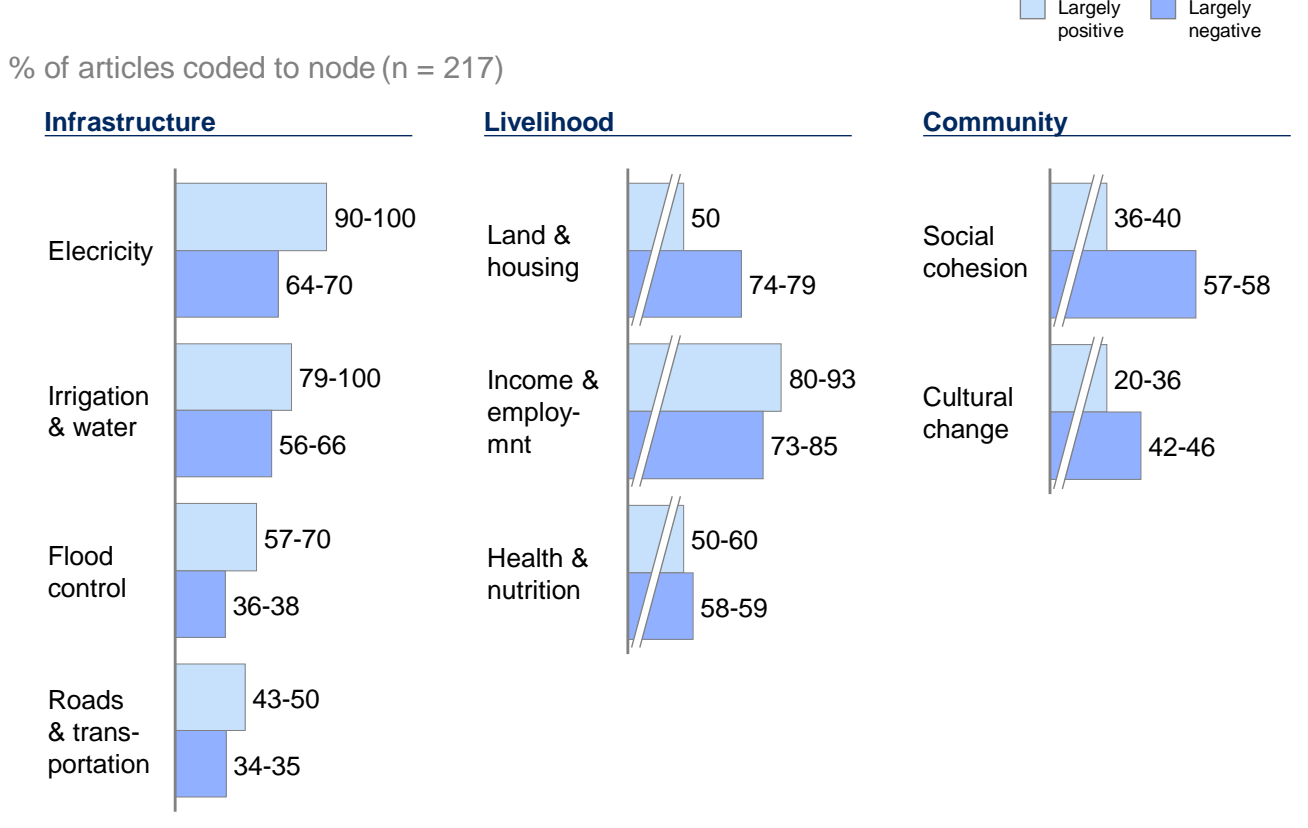

The spatial perspective also differs: $64 \%-70 \%$ of largely positive articles focus on country and global impacts, while only $30 \%-36 \%$ of largely negative articles do so.

\subsection{COMPONENTS OF SOCIAL IMPACT}

No analyses on the social impact of dams can focus on all the components of social impact. However, authors ought to justify themselves when deciding to omit components of social impact in order to allow readers to contextualize the analysis. Herein, an example of best practice may be Strobl and Strobl (2011, p. 449). The authors note in their concluding remarks that "we have not addressed such important issues as the displacement of people, the impact on fishing, and river line erosion, amongst other negative impacts. A comprehensive assessment [...] necessitates a credible quantitative analysis of all of these factors."

However, many authors do not make such acknowledgements. Rather, a listing of social impact components is provided in the beginning of the article presenting the impression that it may be exhaustive, whereas various components of social impact are usually missing. Our analysis focuses on the components of social impact outlined in Figure 1: infrastructure, livelihood and community.

\section{A. INFRASTRUCTURE}


Infrastructure impacts are largely addressed within our sample. 88\%-89\% of articles address this impact, compared to $91 \%-95 \%$ of articles focusing on livelihood impacts as well as $63 \%$ of articles focusing on community impacts. The prominence of infrastructure impacts in our sample may be driven by the focus of scholars on large multi-purpose dams such as the Three Gorges Dam.

These values may over-represent the actual prominence of infrastructure impacts within the literature, though. Due to our conservative approach to coding, we assigned any article that briefly mentioned any infrastructure impact to the infrastructure node. An example that illustrates this coding approach is Bisht (2009). The author explores the disempowerment of women due to resettlement employing the Tehri dam in India as a case study. Regarding electricity production, it is only stated that "the dam provides electricity as well as water for irrigation and drinking." Nevertheless, we coded this article for both the electricity as well as the irrigation and water nodes to avoid deflating any values. In-depth discussions of electricity and other infrastructure impacts are in fact non-existent within our sample.

\section{B. LIVELIHOOD}

Livelihood impacts are largely addressed within our sample. Land and housing impacts are discussed in $72 \%-77 \%$ of the articles. Income and employment is the most frequent component mentioned, with $82 \%-87 \%$ of articles addressing this impact. This prominence may be driven by the recent growth in literature on benefit sharing with affected communities, which, again, may be driven by "sponsors increasingly [recognizing] the need for directly sharing project benefits with local communities" (Égré et al., 2007, p. 235). ${ }^{5}$

Lerer and Scudder (1999, p. 113) argue that the health impacts of dams "are receiving increasing international attention". However, health and nutrition impacts remain the least studied livelihood impacts within our sample or articles. Only 55\%-56\% of articles consider these impacts, 27\%-31\% less than for income and employment and $17 \%-21 \%$ less than for land and housing. This may also be a reflection of our sample frame, though. After all, we did not explicitly search for health impacts during our key word search. Nevertheless, our sample still contains a handful of articles which solely focused on health impacts. An example besides Lerer and Scudder (1999) - is Erlanger et al. (2008); the authors assess the health impacts of the Nam Theun 2 dam in Laos.

5 A topic possibly understudied within income and employment may be corruption in the hydropower sector. A rare example investigating this topic is Transparency International (2008). 
An aspect of health and nutrition entirely not represented in our sample is food security. Indeed, not a single author within our sample focused their analysis solely on the implications of irrigation, water provision or flood control for food security in the resettlement area, upstream region, downstream region or nation. Again, this may be a reflection of our sample frame, because we did not explicitly search for food security during our key word search. The lack of articles on food security within our sample indicates that social impacts tend to be viewed very narrowly by those scholars devoting their analyses explicitly to the social impact of dams.

Lastly, we also find that there is no intersection of the literature on social impacts (in our sample) with that on reservoir management, such as the trade-off between hydropower generation and water for irrigation. Reservoir management literature seems to more commonly focus on environmental impacts such as the historic pulse flow release from the Hoover Dam in 2014 (Howard, 2014).

\section{COMMUNITY}

Social cohesion impacts are discussed by 53\%-54\% of articles. Cultural change impacts are only discussed by 35\%-39\% of articles - the least acknowledged social impact component within our set of components. Downing and GarciaDowning (2009) point out that scholars pay little attention to psycho-socio-cultural impoverishment inflicted by involuntary displacement.

There is a strong link to the dimension of space in the community analyses. 87\%$92 \%$ of articles addressing social cohesion discuss this impact component from a resettlement perspective, compared to only $16 \%$ from an upstream and $22 \%-29 \%$ from a downstream perspective. Meanwhile, $91 \%-92 \%$ of articles on cultural change discuss this impact from a resettlement perspective, compared to $16 \%-21 \%$ from an upstream and 31\%-35\% from a downstream perspective. We hypothesize that a key reason for this link may be that community impacts are mostly studied by anthropologists who mostly focus on the resettlement area when investigating the social impact of dams.

\subsection{UNIT OF ANALYSIS}

The Unit of Analysis reflects the groups focused on within each article, including the private sector (with a particular focus on dam developers), civil society (including NGOs, resettled communities, with a particular focus on vulnerable groups, i.e. women, indigenous and landless people) or government (e.g. domestic government, foreign government and international donors). 
In line with the high value obtained for the resettlement area in the space dimension, resettled communities are by far the most studied unit of analysis within the literature. Indeed, $77 \%-82 \%$ of articles focus on them. Within the civil society node, vulnerable groups are also prominent with $35 \%-47 \%$ of articles coded within this node. NGOs are addressed by $24 \%-27 \%$ of our articles, as depicted in Figure 6.

FIGURE 6: UNIT-OF-ANALYSIS FOCUS WITHIN THE SCHOLARLY LITERATURE

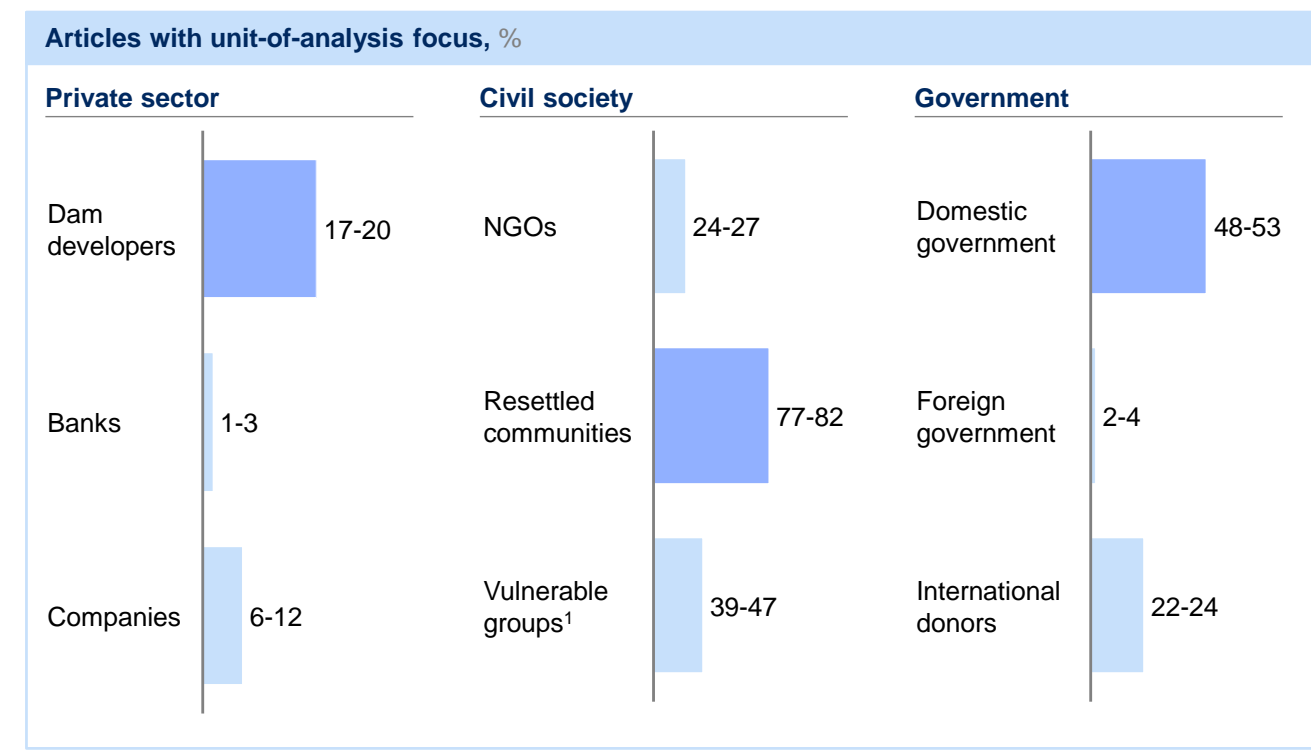

1 Women: $13 \%-17 \%$; Indigenous people: $33-35 \%$, Landless: $8 \%-11 \%$

McCully (2001, p. 144) notes that "surprisingly little research has been carried out on how women and men are differently impacted by dams". Indeed, only $13 \%$ $17 \%$ of articles address women as a particularly vulnerable group. An excellent example of an article discussing the social impacts of the Three Gorges Dam from a woman's perspective is Du (2010), published in Women's Studies Quarterly. Of the 16 articles in our sample on the Three Gorges Dam, only two discuss social impacts from women's perspectives.

Meanwhile, 33\%-35\% of articles focus on indigenous people. 8\%-11\% of articles address landless people, the lowest value within the vulnerable groups node. NGOs repeatedly point out that this group requires more attention. After all, in order to be eligible for any compensation within most resettlement schemes, land must usually be owned. 
Within the government node, domestic governments are discussed in about half of the articles in our sample. Only 2\%-4\% focus on the role of foreign governments, though. This seems surprising, particularly with regard to the current boom of dam construction in the Mekong River Basin (and the Mekong River Commission as the inter-governmental agency attempting to balance the interests of the different countries in the basin).

$22 \%-24 \%$ of articles focus on the role of international donors. More articles with this focus have been published in recent years, possibly reflecting the World Bank's decision to restart investments in hydropower. Indeed, 27\%-31\% of all articles focusing on international donors were published from 2011 to 2015; the expected value within a uniform distribution would be $20 \%$.

Within the private sector, dam developers are the most studied unit of analysis, with $17 \%-20 \%$ of articles coded to that node. Again, this value may over-represent the actual number of papers dedicated to dam developers. Due to our conservative approach, we coded even articles that only briefly mentioned the developer constructing the dam in question into this node.

A closer look at those articles coded to the node 'dam developers' reveals that Chinese hydro-players may be under-represented. Although these players nowadays dominate the global dam industry with the Chinese state-owned enterprise Sinohydro claiming to capture more than $50 \%$ of the global dam developer market (Verhoeven, 2015, p. 178), almost no papers investigate their views on social impact, the social impact assessments (SIAs) conducted or subcontracted by them, or relevant resettlement schemes.

\section{DISCUSSION}

A mature literature on the social impact of dams has developed since the 1960s. The various analyses on the topic are invaluable for our understanding regarding the implications of dam infrastructure. Our analyses indicate that scholars mostly focus on electricity, irrigation and water, land and housing, and income and employment impacts when studying the social impacts of dams. These components of social impacts tend to be studied in the resettlement area after project completion; indeed, this stage requires special attention since "during those initial years the global experience is for living standards of the majority to worsen” (Scudder, 2012, p. 39). Accordingly, a particular emphasis is given to negative social impacts by most scholars. 
Meanwhile, upstream and downstream social impacts of dams remain particularly under-researched with less than a third of articles in our sample addressing them. Similarly, planning and design phase impacts are barely studied (also with less than a third of articles in our sample taking them into account) (Figure 7). These under-researched areas may significantly narrow scholars' conceptualization of the social impacts of dams, which, in turn, may also narrow and skew practitioners' and the public's understanding of those impacts.

\section{FIGURE 7: MAPPING THE RESEARCH ON THE SOCIAL IMPACT OF DAMS}

Underresearched (<33\% of articles) $\square$ Researched (34\%-67\% of articles) $\quad$ Well researched ( $>67 \%$ of articles)

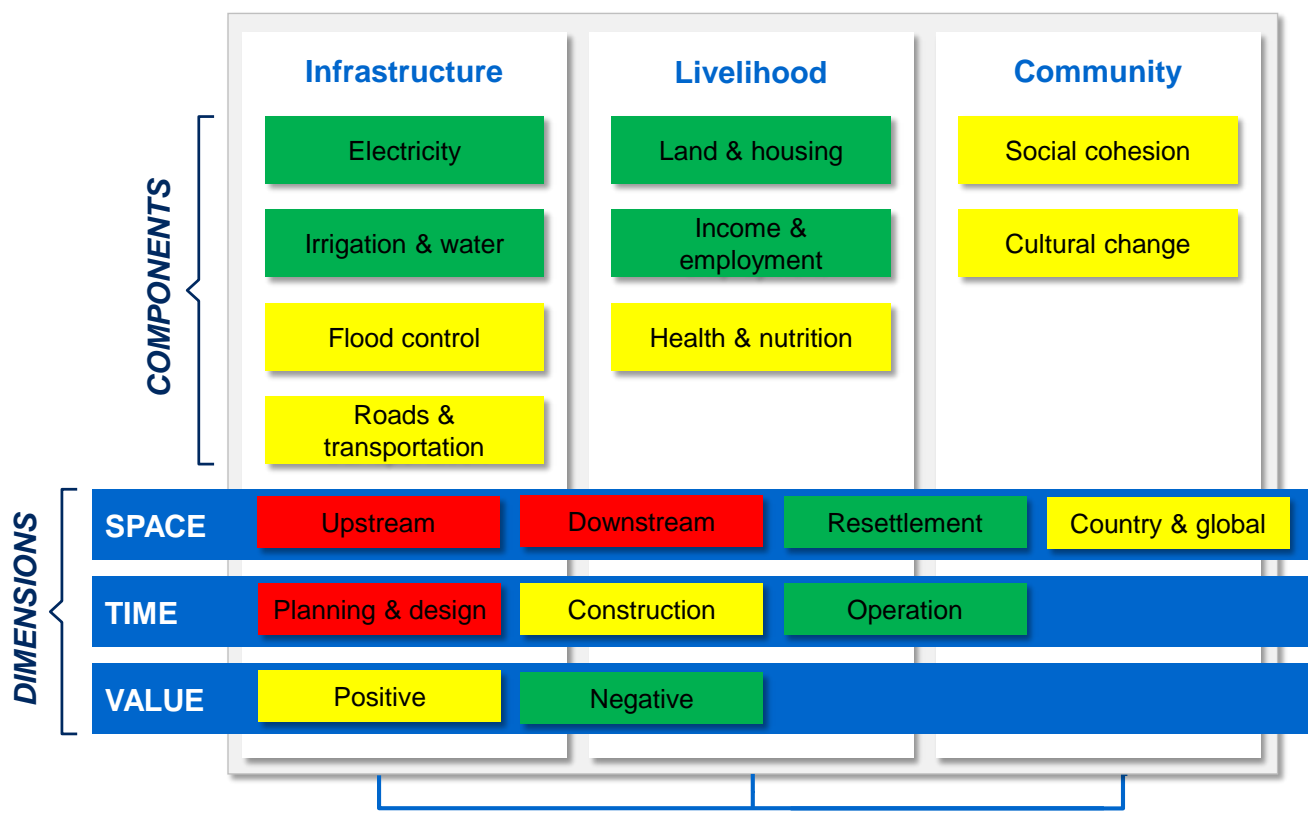

SOURCE: Authors' depiction; Kirchherr \& Charles (2016)

Neglecting upstream and downstream impacts could be problematic both for positive and negative impacts. If water use of populations upstream is restricted in order to fill the reservoir, for instance, these populations would then need to be compensated (Duflo and Pande, 2007, p. 602) - scholars and practitioners may not even think about these populations, though, if upstream impacts are routinely neglected in the literature. If populations downstream benefit from additional irrigation or flood control or suffer from decreasing fish productivity (Ziv et al., 2012), these are also impacts that need to be taken into account in assessing the total social impact of a dam. Neglecting these impacts may lead to a different overall assessment regarding the viability of a project. The full picture regarding dams' social impacts can only be seen and sustainable project management can only be implemented if upstream and downstream impacts are also taken into account. 
Similarly, scholarly studies ignoring planning and design phase impacts may lead to practitioners also ignoring them. Psychological stress (associated with higher death rates among the elderly) was reported by Scudder (2012, p. $40 \mathrm{ff}$.) and is part of his four-stage relocation framework. An equitable resettlement scheme (including both compensation and various development initiatives (Scudder, 2012, p. 60)) would need to address and compensate for these ex-ante resettlement impacts. Similarly, articles in our sample have not analysed second generation social impacts of dams. Media reports on the Grand Coulee Dam in the United States indicate that dams' social impacts may last for up to 70 years (Holdman, 2011). Thus, resettlement schemes must adopt a similar time horizon. Again, the full picture regarding dams' social impacts can only be seen and sustainable project management can only be implemented if planning and design phase as well as long-term social impacts are also taken into account.

This 'full picture' can also be skewed by scholars via the choice of case studies. Single case study research on extremely large dams is particularly popular among academics, we found, with $58 \%$ of single-case-study articles focusing on dams with a height of more than 150 meters. The impacts of these mega-dams may be quite different to those of average large dams, possibly inducing a skewed view regarding dams' average social impacts not only among scholars, but also practitioners. If the social impacts of large dams with varying heights were studied simultaneously, this may lead to a more balanced picture regarding dams' average social impacts.

Studying social impacts will always remain more an art than a science. Several of the social impact components we discussed are difficult to quantify, most notably our alleged community impacts. Because of this 'fuzziness' it is important to gather different narratives and perspectives on dams' social impacts in order to develop a balanced picture regarding the projects' overall social implications. From our research, most scholarly research (77\%-82\%) gives a voice to affected communities. These views are likely to be particularly negative regarding a project where the dam project constitutes a significant upheaval in the life of these communities. The role of foreign governments as well as (development) banks funding dam projects remains under-explored. Similarly, scholars barely take into account the perspective of dam developers, particularly Chinese dam developers, key players in the contemporary global dam industry. Taking into account the perspectives of various stakeholders (from affected communities to dam developers) regarding the social impact of dams may help to make analyses more objective. 


\section{CONCLUSION}

Dam construction entails social impacts, which may be positive or negative. Perceptions of the social impacts of dams are driven in large part by the scholarly literature that addresses those impacts. Biases and research gaps in this literature may undermine the usefulness and credibility of analyses of the social impacts of dams. This paper presents the first systematic review of the literature on the social impact of dams. For this purpose, we built a sample of 217 articles via key word searches, expert consultations and bibliography reviews. All articles were assessed based upon the aggregate matrix framework on the social impact of dams developed by Kirchherr and Charles (2016).

The typical article on the social impact of dams was published in the past 10 years and investigates the resettlement implications of a single extremely large dam in Asia via a qualitative approach 5-10 years after project completion and concludes that these impacts are largely negative. The authors of such a typical article focus mostly on livelihood impacts. Meanwhile, scholars have largely ignored upstream and downstream social impacts. The same holds true for social impacts occurring during the planning and design phase and next generation social impacts. The perspective of foreign governments, (development) banks and (Chinese) dam developers is also frequently ignored. Ignoring various spatial and time perspectives as well as the perspectives of key stakeholders involved in a dam project may lead to skewed overall assessments regarding the viability of a dam project.

In a conference on African dams and development, hosted by the University of Oxford in late 2014, all panelists - indeed, those supporting as well as those opposing the construction of large dams - agreed that more evidence is needed on the topic at hand. But this new evidence should not just be restricted to projects on resettlement for development of a large dam. The current bias in the literature does a disservice to the people who experience positive impacts from dam development, and those negatively impacted other than by resettlement from large dams. Decisions are taken to pursue small dams over large dams, or to export dam construction to neighbouring countries, without a full understanding of the tradeoffs involved because of incomplete literature on the subject. We argue that there particularly needs to be a shift in the literature to address the positive and negative social impacts of dams, and for dams of different sizes analysing their impacts from various spatial dimensions, to enable better explication of the trade-offs that occur in the development of these infrastructure projects. 


\section{ACKNOWLEDGEMENTS}

This research was funded by Friedrich Naumann Foundation. We would like to thank James Fenske, Nathanial Matthews, Christine McCulloch, and Judith Plummer for their suggestions regarding our sample of articles. We would also like to thank Judith Plummer for suggestions and comments on parts of this paper. Furthermore, we are grateful to those providing feedback to this paper at the University of Sheffield RGS-IBG Forum Mid-Term Conference 2015 in March 2015, those at the University of Oxford Water Talk in May 2015 as well as those at HYDRO 2015 in October 2015. We are also grateful to two anonymous reviewers at Environmental Impact Assessment Review for their constructive comments on this piece of work and their suggestions regarding our sample.

\section{DISCLOSURE STATEMENTS}

No potential conflicts of interest were reported by the authors.

\section{BIBLIOGRAPHY}

Abbasi, T., \& Abbasi, S. A. (2011). Small hydro and the environmental implications of its extensive utilization. Renewable and Sustainable Energy Reviews, 15(4), 2134-2143.

Adeniyi, E. O. (1976). The Kainji Dam: an exercise in regional development planning. Regional Studies, 10(2), 233-243. http://doi.org/10.1080/09595237600185231

Ansar, A., Flyvbjerg, B., Budzier, A., \& Lunn, D. (2014). Should We Build More Large Dams? The Actual Costs of Hydropower Megaproject Development. Energy Policy. Retrieved from http://papers.ssrn.com/abstract=2406852

Bakker, K. (1999). The politics of hydropower: developing the Mekong. Political Geography, 18(2), 209-232. http://doi.org/10.1016/S0962-6298(98)00085-7

Barrow, C. J. (2000). Social Impact Assessment - An Introduction. London: Arnold.

Bartolome, L. J., Wet, C. de, Mander, H., \& Nagraj, V. K. (2000). Displacement, Resettlement, Rehabilitation, Reparation, and Development. Retrieved from http://siteresources.worldbank.org/INTINVRES/Resources/DisplaceResettleR ehabilitationReparationDevFinal13main.pdf 
Beck, M. W., Claassen, A. H., \& Hundt, P. J. (2012). Environmental and livelihood impacts of dams: common lessons across development gradients that challenge sustainability. International Journal of River Basin Management, 10(1), 73-92. http://doi.org/10.1080/15715124.2012.656133

Beyea, S. C., \& Nicoll, L. H. (1998). Writing an integrative review. AORN Journal, 67(4), 877-880. http://doi.org/10.1016/S0001-2092(06)62653-7

Bisht, T. C. (2009). Development-Induced Displacement and Women: The Case of the Tehri Dam, India. The Asia Pacific Journal of Anthropology, 10(4), 301317. http://doi.org/10.1080/14442210903271312

Biswas, A. K. (1997). Water Resources: Environmental Planning, Management, and Development. McGraw-Hill Professional.

Cernea, M. (1990). Poverty risks from population displacement in water resources development. Working Paper. Retrieved from http://www.popline.org/node/379181

Cernea, M. (2004). Social Impacts and Social Risks in Hydropower Programs: Preemptive Planning and Counter-risk Measures. Retrieved from http://www.un.org/esa/sustdev/sdissues/energy/op/hydro_cernea_social impacts_backgroundpaper.pdf

Cleetus, R., Clemmer, S., Davis, E., Deyette, J., Downing, J., \& Frenkel, S. (2012). Ripe for Retirement - The Case for Closing America's Costliest Coal Plants. Retrieved from http://www.ucsusa.org/sites/default/files/legacy/assets/documents/clean_energ y/Ripe-for-Retirement-Full-Report.pdf

Colchester, M. (2000). Sharing Power: Dams, Indigenous Peoples and Ethnic Minorities. Retrieved from http://www.forestpeoples.org/sites/fpp/files/publication/2010/08/damsipsethni cminoritiesnov00eng.pdf

Colson, E. (1971). The social consequences of resettlement. Manchester University Press.

CPI. (2011). Environmental Impact Assessment for Myitsone Dam. Retrieved from http://www.scribd.com/doc/66851933/Environmental-Impact-Assessmentfor-Myitsone-Dam 
Cronin, P., Ryan, F., \& Coughlan, M. (2008). Undertaking a literature review: a step-by-step approach. British Journal of Nursing (Mark Allen Publishing), 17(1), 38-43. http://doi.org/10.12968/bjon.2008.17.1.28059

De Wet, C. (2006). Development-induced displacement : problems, policies and people. Oxford: Berghahn Books.

De Wet, C. (2012). The Application of International Resettlement Policy in African Villagization Projects. Human Organization, 71(4), 395-406. http://doi.org/10.17730/humo.71.4.0787k13246877275

Downing, T. E., \& Garcia-Downing, C. (2009). Routine and dissonant cultures: A Theory about the psycho-socio-cultural disruptions of involuntary displacement and ways to mitigate them without inflicting even more damage. Development and Dispossession: The Anthropology of Displacement and Resettlemen. Retrieved from http://allthingsaz.com/wpcontent/uploads/2012/01/Routine-and-Dissonant-Culture-T-Downing-and-CGarciaDowning1.pdf

Du, D. Y. (2010). Documenting Three Gorges Migrants: Gendered Voices of (Dis)placement and Citizenship in Rediscovering the Yangtze River and Bingai. WSQ: Women's Studies Quarterly, 38, 27-47.

Duflo, E., \& Pande, R. (2007). Dams. The Quarterly Journal of Economics, 122(2), 601-646. http://doi.org/10.1162/qjec.122.2.601

Égré, D., Roquet, V., \& Durocher, C. (2007). Monetary benefit sharing from dams: A few examples of financial partnerships with Indigenous communities in Québec (Canada). International Journal of River Basin Management, 5(3), 235-244. http://doi.org/10.1080/15715124.2007.9635323

Égré, D., \& Senécal, P. (2003). Social impact assessments of large dams throughout the world: lessons learned over two decades. Impact Assessment and Project Appraisal, 21(3), 215-224. http://doi.org/10.3152/147154603781766310

Erlanger, T. E., Sayasone, S., Krieger, G. R., Kaul, S., Sananikhom, P., Tanner, M., ... Utzinger, J. (2008). Baseline health situation of communities affected by the Nam Theun 2 hydroelectric project in central Lao PDR and indicators for monitoring. International Journal of Environmental Health Research, 18(3), 223-42. http://doi.org/10.1080/09603120701757815 
Esteves, A. M., Franks, D., \& Vanclay, F. (2012). Social impact assessment: the state of the art. Impact Assessment and Project Appraisal, 30(1), 34-42. http://doi.org/10.1080/14615517.2012.660356

Finley-Brook, M., \& Thomas, C. (2011). Renewable Energy and Human Rights Violations: Illustrative Cases from Indigenous Territories in Panama. Annals of the Association of American Geographers, 101(4), 863-872. http://doi.org/10.1080/00045608.2011.568873

Glass, G. (1976). Primary, Secondary, and Meta-Analysis of Research. Educational Researcher, 5(10), 3-8.

Gleick, P. H. (1992). Environmental consequences of hydroelectric development: The role of facility size and type. Energy, 17(8), 735-747.

Greathouse, E. A., Pringle, C. M., McDowell, W. H., \& Holmquist, J. G. (2006). Indirect upstream effects of dams: consequences of migratory consumer extirpation in Puerto Rico. Ecological Applications : A Publication of the Ecological Society of America, 16(1), 339-52. Retrieved from http://www.ncbi.nlm.nih.gov/pubmed/16705984

Gunawan, B., Manatunge, J., \& Pratiwi, F. D. (2013). Livelihood status of resettlers affected by the Saguling Dam project, 25 years after inundation. International Journal of Water Resources Development, 29(1), 25-34. http://doi.org/10.1080/07900627.2012.738593

Holdman, J. (2011). Spokanes seek new Grand Coulee deal. Retrieved from http://www.spokesman.com/stories/2011/oct/23/spokanes-seek-new-grandcoulee-deal/

Howard, B. C. (2014). Historic "Pulse Flow” Brings Water to Parched Colorado River Delta. Retrieved from http://news.nationalgeographic.com/news/2014/03/140322-colorado-riverdelta-pulse-flow-morelos-dam-minute-319-water/

International Association for Impact Assessment (IAIA). (2014). Social Impact Assessent. Retrieved from http://www.iaia.org/uploads/pdf/KeyCitations_SIA.pdf

Kibler, K. M., \& Tullos, D. D. (2013). Cumulative biophysical impact of small and large hydropower development in Nu River, China. Water Resources Research, 49(6), 3104-3118. http://doi.org/10.1002/wrcr.20243 
Kirchherr, J., \& Charles, K. (2016). The Social Impact of Dams: A New Framework for Scholarly Analysis. Environmental Impact Assessment Review.

Larsen, P. O., \& von Ins, M. (2010). The rate of growth in scientific publication and the decline in coverage provided by Science Citation Index. Scientometrics, 84(3), 575-603. http://doi.org/10.1007/s11192-010-0202-z

Lerer, L. B., \& Scudder, T. (1999). Health impacts of large dams. Environmental Impact Assessment Review, 19(2), 113-123. http://doi.org/10.1016/S01959255(98)00041-9

Matthews, N. (2013). PhD thesis (embargoed).

McAdam, D., Boudet, H. S., Davis, J., Orr, R. J., Richard Scott, W., \& Levitt, R. E. (2010). "Site Fights": Explaining Opposition to Pipeline Projects in the Developing World. Sociological Forum, 25(3), 401-427. http://doi.org/10.1111/j.1573-7861.2010.01189.x

McCully, P. (2001). Silenced Rivers: The Ecology and Politics of Large Dams. Palgrave Macmillan.

Nombre, A. (2014). Yes, we need to build more large dams for water storage and energy for sustainable development! Retrieved from http://www.icoldcigb.org/share/article/0/icold-president-answers-oxford-misleading-study

Nüsser, M. (2003). Political Ecology of Large Dams: a Critical Review. Retrieved from http://www.sai.uniheidelberg.de/geo/pdfs/Nuesser_2003_PoliticalEcologyOfLargeDams_PGM_ 147(1)_20-27.pdf

Pitt, D. (2013). Hydroelectric Power Making A Comeback As Companies Turn To Renewable Energy. The Huffington Post. Retrieved from http://www.huffingtonpost.com/2013/09/12/hydroelectric-powercomeback_n_3911119.html

Plummer, J. (2013). Assessing the Effects of Pre-construction Delay in Hydropower Projects. Cambridge: Department of Engineering, Centre for Sustainable Development, University of Cambridge.

Qi, H., \& Altinakar, M. S. (2012). GIS-Based Decision Support System for Dam Break Flood Management under Uncertainty with Two-Dimensional Numerical Simulations. Journal of Water Resources Planning and 
Management, 138(4), 334-341. http://doi.org/10.1061/(ASCE)WR.19435452.0000192

Richter, B. D., Postel, S., Revenga, C., Scudder, T., Lehner, B., Churchill, A., \& Chow, M. (2010). Lost in Development's Shadow: The Downstream Human Consequences of Dams. Water Alternatives, 3(2), 14-42. Retrieved from http://www.water-alternatives.org/index.php/volume3/v3issue2/80-a3-2-3/file

Sabnis, S. (2001). Environmental Overview of the Sardar Sarovar Project. Retrieved from http://ezproxyprd.bodleian.ox.ac.uk:2108/doi/abs/10.1080/713672556\#.VVUk9PIVgSU

Sanyanga, R. (2015). The Inga 3 Hydropower Project. Retrieved from https://www.internationalrivers.org/campaigns/the-inga-3-hydropower-project

Schneider, H. (2013). World Bank rethinks stance on large-scale hydropower projects. The Guardian. Retrieved from http://www.theguardian.com/environment/2013/may/14/world-bankhydropower-dam-rethink

Scudder, T. (1968). Social Anthropology, Man-Made Lakes and Population Relocation in Africa. Anthropological Quarterly, 41(3), 168-176. Retrieved from http://www.jstor.org/stable/3316790?seq=1\&sid=21105100636561\&uid=373 7968\&uid=2\&uid=4\#page_scan_tab_contents

Scudder, T. (1997). Social Impacts. In A. K. Biswas (Ed.), Water Resources: Environmental Planning, Management and Development. McGraw-Hill Professional.

Scudder, T. (2006). The Future of Large Dams: Dealing with Social, Environmental, Institutional and Political Costs. Routledge.

Scudder, T. (2011). Development-induced community resettlement. In F. Vanclay \& A. M. Esteves (Eds.), New Directions in Social Impact Assessment. Cheltenham: Edward Elgar Publishing Limited.

Scudder, T. (2012). Resettlement Outcomes of Large Dams. In C. Tortajada, D. Altinbilek, \& A. K. Biswas (Eds.), Impacts of Large Dams: A Global Assessment. Springer Berlin Heidelberg.

Scudder, T. (2016). Personal communication.

Scudder, T., \& Colson, E. (1982). From Welfare to Development: A Conceptual Framework for the Analysis of Dislocated People. In A. Hansen \& A. Oliver- 
Smith (Eds.), Involuntary Migration and Resettlement: The Problems and Responses of Dislocated People. Boulder, United States: Westview Press.

Scudder, T., Talbot, L. M., \& Whitmore, T. C. (1997). Report of the International Environmental and Social Panel of Experts. Retrieved from http://wwwwds.worldbank.org/external/default/WDSContentServer/WDSP/IB/2000/11/1 0/000094946_00101705305674/Rendered/PDF/multi_page.pdf

Shields, M. A. (1974). Social Impact Studies: An Expository Analysis.

Environment and Behavior. Retrieved from http://eric.ed.gov/?id=EJ128316

Singg, R. N., \& Webb, B. R. (1979). USE OF DELPHI METHODOLOGY TO ASSESS GOALS AND SOCIAL IMPACTS OF A WATERSHED

PROJECT. Journal of the American Water Resources Association, 15(1), 136-143. http://doi.org/10.1111/j.1752-1688.1979.tb00294.x

Sleesman, D. J., Conlon, D. E., McNamara, G., \& Miles, J. E. (2012). Cleaning Up the Big Muddy: A Meta-Analytic Review of the Determinants of Escalation of Commitment. Academy of Management Journal, 55(3), 541562. http://doi.org/10.5465/amj.2010.0696

SRP. (2015). Theodore Roosevelt Dam. Retrieved from http://www.srpnet.com/water/dams/roosevelt.aspx

Strobl, E., \& Blanc, E. (2013). Is small better ? a comparison of the effect of large and small dams on cropland productivity in South Africa, 1-53. Retrieved from http://documents.worldbank.org/curated/en/2013/08/18104538/smallbetter-comparison-effect-large-small-dams-cropland-productivity-south-africa

Strobl, E., \& Strobl, R. O. (2011). The distributional impact of large dams: Evidence from cropland productivity in Africa. Journal of Development Economics, 96(2), 432-450. http://doi.org/10.1016/j.jdeveco.2010.08.005

Sutton, K. (1977). Population Resettlement — Traumatic Upheavals and the Algerian Experience. The Journal of Modern African Studies, 15(02), 279300. Retrieved from http://journals.cambridge.org/abstract_S0022278X00053945

Tajziehchi, S., Monavari, S. M., Karbassi, A. R., Shariat, S. M., \& Khorasani, N. (2013). Quantification of Social Impacts of Large Hydropower Dams- a case study of Alborz Dam in Mazandaran Province, Northern Iran. International Journal of Environmental Research, 7(2), 377-382. Retrieved from http://www.ijer.ir/article_615_7.html 
Takesada, N. (2009). Japanese Experience of Involuntary Resettlement: LongTerm Consequences of Resettlement for the Construction of the Ikawa Dam. International Journal of Water Resources Development, 25(3), 419-430. http://doi.org/10.1080/07900620902965459

Tilt, B., Braun, Y., \& He, D. (2009). Social impacts of large dam projects: a comparison of international case studies and implications for best practice. Journal of Environmental Management, 90 Suppl 3, S249-57. http://doi.org/10.1016/j.jenvman.2008.07.030

Transparency International. (2008). Global Corruption Report 2008 - Corruption in the Water Sector. Retrieved from http://resources.transparency.bg/download.html?id=240

Tullos, D., Brown, P. H., Kibler, K., Magee, D., Tilt, B., \& Wolf, A. T. Perspectives on the salience and magnitude of dam impacts for hydro development scenarios in China, 3 Water Alternatives 71 - 90 (2010).

Tullos, D. D., Foster-Moore, E., Magee, D., Tilt, B., Wolf, A. T., Schmitt, E., ... Kibler, K. (2013). Biophysical, Socioeconomic, and Geopolitical Vulnerabilities to Hydropower Development on the Nu River, China. Ecology and Society, 18(3), art16. http://doi.org/10.5751/ES-05465-180316

Urban, F., Nordensvärd, J., Khatri, D., \& Wang, Y. (2012). An analysis of China's investment in the hydropower sector in the Greater Mekong Sub-Region. Environment, Development and Sustainability, 15(2), 301-324. http://doi.org/10.1007/s10668-012-9415-z

Vanclay, F. (2002). Conceptualising social impacts. Environmental Impact Assessment Review, 22(3), 183-211. http://doi.org/10.1016/S01959255(01)00105-6

Verhoeven, H. (2015). Water, Civilization and Power in Sudan - The Political Economy of Military-Islamist State Building. Cambridge University Press.

Wang, P., Lassoie, J. P., Dong, S., \& Morreale, S. J. (2013). A framework for social impact analysis of large dams: a case study of cascading dams on the Upper-Mekong River, China. Journal of Environmental Management, 117, 131-40. http://doi.org/10.1016/j.jenvman.2012.12.045

WCD. (2000). Dams and Development - A New Framework for Decision-Making. World Commission on Dams. Retrieved from http://www.internationalrivers.org/files/attachedfiles/world_commission_on_dams_final_report.pdf 
Wiejaczka, Ł., Piróg, D., Soja, R., \& Serwa, M. (2014). Community perception of the Klimkówka Reservoir in Poland. International Journal of Water Resources Development, 30(4), 649-661.

http://doi.org/10.1080/07900627.2014.892426

Ziv, G., Baran, E., Nam, S., Rodríguez-Iturbe, I., \& Levin, S. A. (2012). Tradingoff fish biodiversity, food security, and hydropower in the Mekong River Basin. Proceedings of the National Academy of Sciences of the United States of America, 109(15), 5609-14. http://doi.org/10.1073/pnas.1201423109 